Personalidade Acadêmica Homenageada:

Florisbal de Souza Del'Olmo (Professor Convidado - UNICURITIBA)

\title{
O COMPLIANCE CONSUMERISTA: UTOPIA OU REALIDADE UMA ANÁLISE DO CÓDIGO DE ÉTICA DO WALLMART
}

\section{THE CONSUMERIST COMPLIANCE: UTOPIA OR REALITY ANALYSIS OF THE WALLMART CODE OF ETHICS}

\begin{abstract}
JULIANO DEFFUNE FLENIK
Advogado, membro da comissão de direito tributário da $\mathrm{OAB} / \mathrm{PR}$, Membro da Comissão de Compliance da OAB.PR, Mestrando em Direito Empresarial na Unicuritiba - em Atividade Empresarial e Constituição: inclusão e sustentabilidade. Especialista em Direito Penal e Criminologia - pelo Instituto de Criminologia e Política Criminal, Universidade Federal do Paraná, Especialista em Direito Processual Penal pela Pontifícia Universidade Católica do Paraná - PUC-PR
\end{abstract}

\section{RESUMO}

O presente trabalho busca através do código de ética do Wallmart, bem como de suas políticas mercantis, traçar um novo paradigma da atividade empresarial, seja esta a chamada empresa cidadã. Nesse novo contexto empresarial, o modelo buscado visa à conglobancia da atividade empresarial aliadas à valores intrínsecos e comportamentos extrínsecos que envolvam esse novo papel empresarial afim de consecução de protagonismo social da empresa, e sobretudo a defesa do consumidor.

PALAVRAS-CHAVE: Compliance; Direito Empresarial; Empresa Cidadã; Cidadania. 
Personalidade Acadêmica Homenageada:

Florisbal de Souza Del'Olmo (Professor Convidado - UNICURITIBA)

\begin{abstract}
The present work searches through the code of ethics of Wallmart, as well as of its mercantil policies, to draw a new paradigm of the business activity, be it the socalled citizen company. In this new business context, the model seeks to conglomerate the business activity, together with intrinsic values and extrinsic behaviors that involve this new entrepreneurial role in order to achieve a social role of the company, and above all consumer protection.
\end{abstract}

KEYWORDS: Compliance; Business Law; Citizen Company; Citizenship.

\title{
INTRODUÇÃO
}

A ética é um elemento que desafia o ser humano, em todas as suas épocas, o que impõe cada vez mais conceituar, prescrever e aprimorar o conceito de ética, tornando um elemento de fácil compreensão, capaz de envolver um "novo" ser humano profundamente deslocado de valores na sociedade moderna, bem como, direcionar a atividade empresarial voltada para a cidadania.

Tais disposições, embora, afeta à um panorama de dissociação de valores, da figura humana, e à uma dissociação de valorização da pratica desses valores, conduzem a sociedade, e o ser humano à caminhos de indiferenças frente aos desígnios de sobrevivência que the são impostos. Tal dissociação se deve ao recrudescimento do elemento volitivo do comportamento humano e da sociedade.

A este comportamento, contudo reflexivo da era que vivemos, reverbera de forma contundente na estrutura empresarial, constituída sobre a postura humana, que não raras vezes, também vem contaminada pelas distorções ético-morais que afligem o ser humano.

Nessa estrutura humana da empresa, vemos com muita clareza o comportamento empresarial elevado à uma nova dimensão capaz de dar concretude aos valores sociais encontrados na Constituição Federal. Este novo comportamento empresarial está "conformando" o novo cenário de atuação das empresas, tornando- 


\section{Personalidade Acadêmica Homenageada:}

\section{Florisbal de Souza Del'Olmo (Professor Convidado - UNICURITIBA)}

as verdadeiros agentes de pacificação social. A figura humana dentro das empresas, são compreendidas como verdadeiros capital de investimento na atividade fim desta empresa, sendo que os benefícios transbordam a atividade fim, e chegam à uma mudança cultural de dentro para fora da estrutura empresarial.

Nessa ultrapassagem da barreira da conduta humana, o mundo jurídico se vê frente à frente cada vez mais, com situações de impendem de uma analise interpretativa e integrativa da ética e da moral, inclusive, como solução aos litígios contemporâneos, intra e extra corporativo.

Sabedores, das críticas acerca da valoração moral, para solução de litígios, certo é, que há um movimento altruísta no que tange à análise ético moral, e ao que se demonstra irreversível nesse sentido, de tangenciamento valorativo da atividade empresarial, na concretização de seu objeto societário.

Dentro desse novo contexto, parece que o novo contexto parece revelar "em que sentido a ética seja entendida como norma de conduta conducente ao bem, seja como dever ideal. " (LUCCA, 2009, PG. 313).

Claro que a conformidade ética, em nossa atualidade comporta uma gama muito grande de conceitos e julgamentos, que transbordam a análise propriamente do conceito de ética. A grandeza da discussão demonstrada por esse novo cenário, revela acima de tudo "a mudança de comportamento ético, pela prática reiterada" (LUCCA, 2009, pg. 313) de posturas empresariais sejas estas endógenas, exógenas, bem como pela mudança do paradigma jurídico e legal, no espectro empresarial.

Nesse novo cenário, vemos que as dimensões da atividade empresarial sofreram, e ainda sofrem, portanto, um alargamento filosófico, comportando um novo fundamento da atividade empresarial, seja pela dimensão moral, seja pela dimensão econômica, mas sobretudo pelo papel de agente social que a empresa cidadã passa a desenvolver. 
Personalidade Acadêmica Homenageada:

Florisbal de Souza Del'Olmo (Professor Convidado - UNICURITIBA)

\title{
1 FUNÇÃO SOCIAL DA EMPRESA
}

Uma das questões mais controvertidas do Direito Empresarial diz respeito ao que chamamos de função social:

\begin{abstract}
O Código. Civil de 2002 silenciou, infelizmente, por inteiro acerca da função social da empresa, apenas cuidando, no art.: 421, da função SOCIAL do contrato. Caberia 'questionar, destarte, se não FALTADO algo mais a 'respeito daquilo que seria, efetivamente, uma concepção moderna da empresa, vale dizer, não mais aquela ideia clássica de que somente o empresário seria o verdadeiro produtor de bens ou de serviços, com os empregados não passando de seu mero instrumento. É claro que essa visão já se encontra completamente ultrapassada, mas faltam contribuições para que a nova concepção seja levada às últimas consequências. Por exemplo, todo, o problema da função social da empresa nós sabemos, continua sendo mais um exercício de retórica do que concreta, enquanto o poder de controle estiver exclusivamente; na propriedade do capital. (LUCCA, 2009, pg. 323)
\end{abstract}

Infelizmente, a celeuma gira em torno de sua abrangência, que o termo expõe, bem como de uma semântica que não comporta a precisão mais adequada ao que se quer delimitar. Como já citado acima, estamos diante de um novo compromisso social, um novo pacto, o qual precisa de efetividade em sua concretização. A função social, portanto, é a conglobância desse conceito, e sua efetiva materialização no direito brasileiro. Em um exercício de aproximação de conceitos, mas não meramente conceitual, há que se pensar na empresa como "agente social" como anteriormente dito, como "agente pacificador", como "elemento catalisador da sociedade". Cremos que seriam estes as verdadeiras funções sociais atribuídas à empresa.

Essa transcendência de conceitos se realiza não só pela promoção desses valores, mas também pelo apoio e mudança sócio comportamental dos trabalhadores e demais empresas, que a ajudam na atividade fim.

Essa cadeia de produção intrincada pela necessidade técnica, econômica e financeira, e administrativa, é que ramificam e estruturam a chamada função social da empresa. Dessa complexa estrutura socioeconômica é que, portanto, nasce o lucro, é dessa complexa estrutura que se distribui renda, é dessa complexa estrutura 
Personalidade Acadêmica Homenageada:

Florisbal de Souza Del'Olmo (Professor Convidado - UNICURITIBA)

que se muda o comportamento social, sendo este, portanto o último elemento dessa cadeia sócio econômica.

No contexto da Função social da empresa, de forma muito brilhante demonstra-se através do conceito de Responsabilidade Social, que esta assume "proporções muito maiores":

Responsabilidade social significa algo, que nem sempre é a mesma coisa para todos. Para alguns, ela representa a ideia de responsabilidade ou obrigação legal; para outros, significa um comporta responsável no sentido ético; para outros, ainda, o significado transmitido' de 'responsável por', num modo causal. Muitos, simplesmente, tomam pelo sentido de socialmente consciente", daí resultando o grande número, definições existentes. Seja como for, apesar do caráter multívoco da expressão, dúvida inexiste quanto ao seu caráter analógico, sempre no sentido de que se trata de imperativo categórico - para usar a dicção kantiana - para as empresas reconhecem seu indeclinável dever de atuar em benefício da comunidade qual se acham inseridas. (LUCCA, 2009, pg. 325)

Vejamos, portanto, que a empresa deve ser vista como agregador de valor na comunidade onde está inserida, mas não pela obrigação social pura e simplesmente, mas como representante de uma atividade "multívoca" e de reconhecido benefício social. Dentro desse espectro a função social toma, portanto, um novo direcionamento, seja pelo aspecto promocional social que a ela está atrelada, seja pelo aspecto valorativo que esta promove.

Nesse diapasão entre postura empresarial e função social, vemos com muita clareza que a atividade empresarial pautada eticamente por condutas morais e pelo respeito ao ordenamento, se torna, portanto, o verdadeiro catalisador social necessário à concretização dos direitos sociais insculpidos na Constituição Federal.

Por outro lado, mas embora no sentido da atuação ética da empresa, há que se fazer, especial menção sobre o respeito à legalidade. Tal princípio de direito, a legalidade é limite e via a ser seguido pela conformação da função social da empresa, a qual mitiga eventuais infrações legais, simplesmente pela pauta ética que à conduz. Vejamos, portanto, que a inserção do elemento ético "a priori" conduz a propagação de prevenção a violações legais que possam trazer prejuízos à empresa. Desta feita a postura ética é senão elemento engajador da postura e do cumprimento do imperativo da norma como obrigação empresarial. 
Personalidade Acadêmica Homenageada:

Florisbal de Souza Del'Olmo (Professor Convidado - UNICURITIBA)

Corroborando inclusive a ordem jurídica, certo é também que a efetivação desses valores dentro da empresa, transformam o cenário econômico, transformam o mercado, e estabelecem novas praticas que protegem a própria empresa de eventuais problemas de não conformidade legal. Acrescente-se ainda, que aqui reside o novo olhar do compliance empresarial, onde é retirar a atividade empresarial do espectro da desconformidade legal.

Vejamos, que a desconformidade legal, é elemento estranho para a empresa com relevância ética em sua atividade. Ou seja, atuar eticamente, é além de ter preocupação social, mas é atuar conforme as normas legais, mitigando eventuais danos a empresa.

No contexto empresarial as dimensões da chamada responsabilidade social, portanto, ou função social da empresa, se expandem em direções diversas, as quais demonstram perspectivas internas e externas de conformação da atividade empresária, seja de cunho meramente administrativo, ou de conformação legal, com seu consumidor final e seus fornecedores, bem como o mercado, seus empregados e a sociedade.

Vejamos, que a amplitude da ação ética da empresa revela, uma cobertura de todas as ações empresarias, que vão desde a sua realização empresarial, até a entrega de seu produto final, perquirindo ainda o trato ético na sua eficiência.

Nesse ínterim, "Pode-se dizer que a eficiência não é só 'fazer as coisas bem', segundo as regras do mercado, mas é 'fazer as coisas boas' segundo princípios éticos. " (LUCCA, 2009, pg. 333)

Isso é o que chamamos em direito empresarial de "ciclo virtuoso de responsabilidade social, em um ambiente de Justiça Social. " (LUCCA, 2009, pg. 333). Essa é uma estratégia para demonstrar o papel que a empresa passa a ocupar com a carta Constitucional de 1988, onde o pós-positivismo engendra uma leitura Constitucional à luz dos valores insculpidos naquela matriz legal, na qual exerce um papel de protagonismo social. 
Personalidade Acadêmica Homenageada:

Florisbal de Souza Del'Olmo (Professor Convidado - UNICURITIBA)

\section{POSSIBILIDADE DE UMA ÉTICA PARA A EMPRESA}

Diante de tudo o que foi exposto, nos parece, portanto, ser possível a construção de uma ética empresarial capaz de conduzir a atividade comercial à um novo parâmetro:

Mas, a par das considerações de caráter moral, torna-se necessário investigar, também, se a ética empresarial constitui ou não um bom negócio para as empresas. Vejamos a posição de alguns autores a respeito da matéria. $O$ Professor José Henrique Silveira de Brito, por exemplo, assinala:"Ver na Ética um caminho para promover as empresas aos olhos da opinião pública não é uma fantasia, uma miragem. Uma empresa que põe em primeiro lugar os seus clientes, que respeita 0 meio ambiente, que reconhece ter uma responsabilidade social, que se preocupa com a vida cultural dos seus trabalhadores, que está atenta a todos os que, direta ou indiretamente, têm alguma relação com ela, melhora a sua imagem e tira disso benefícios de diversa índole e, entre eles, benefícios econômicos. (LUCCA, 2009, pg.338)

Vejamos, que esse parâmetro de abrangência empresarial deve ser perseguido, incessantemente, pois tornou-se um verdadeiro ativo da empresa o ambiente ético construído pela mesma. Acredita-se, portanto, que tais atividades mercantis são perfeitamente praticáveis através de uma "práxis" efetivamente voltada à princípios que conformam novamente uma preocupação à valores éticos de comportamento supramorais ${ }^{1}$.

No que tange às considerações morais, ou condutas moralmente relevantes, tornar-se necessário, uma observação do custo desta opção de conduta dentro das empresas. Fato é que, as condutas moralmente elevadas, demonstraram-se, como já dito anteriormente, ao longo do tempo, "ativos empresariais", os quais tornaram as empresas verdadeiros objetos de desejos de investidores e trabalhadores.

Já no que tange aos custos, para implementação de programas de integridade, estes devem ser avaliados como forma de investimento pela empresa, a

\footnotetext{
${ }^{1}$ Adota-se essa expressão de supramoralidade, na tentativa de elevar valores de comportamento calcado nas mais diversas morais existentes. Assim aportamos a supra moralidade a consecução do bem, em contrapartida de uma moralidade sectária, propiciada geralmente pela religião, ou sistemas de controle social. Acrescente-se a supramoralidade, algo superior com valores estoicos e que possam convergir todos os outros sistemas morais a concreção da pratica do bem comum.
} 
Personalidade Acadêmica Homenageada:

Florisbal de Souza Del'Olmo (Professor Convidado - UNICURITIBA)

qual captara através desta nova face da empresa o retorno econômico pretendido, bem como os benefícios econômicos almejados.

No aspecto mercantil, a ética e moralidade empresarial, se vistos dessa forma, traduzem, portanto, despesas em um primeiro momento, mas demonstrariam verdadeiros investimentos no ativo intangíveis da empresa, que se incorporariam como valores de mercado na empresa. Esse investimento na mudança sóciocomportamental da empresa possui um valor de retorno maior visto que além do ambiente de trabalho mais hígido, a prevenção de riscos à integridade da empresa supera valores que eventualmente possam surgir em razão de riscos efetivamente gerados ou ocasionados por condutas não conformadas.

Vejamos também que um ambiente equilibrado e pautado por valores mais elevados, traduzem um ambiente de segurança no trabalho, o que acarreta em aumento na produtividade.

O primeiro deles estaria relacionado com a diminuição dos custos referentes ao controle. Quando os recursos humanos estão motivados por um forte e saudável espírito ético, a empresa não necessita despender tantos recursos financeiros com os sistemas de vigilância da produtividade nem tampouco com relógios de ponto para controle de entrada e fie saída de seu funcionário. $\mathrm{O}$ segundo desses fatores, que se interpenetra necessariamente com o primeiro, diz respeito ao aumento da produtividade. É muito conhecida de todos aquela história de dois trabalhadores que executavam a mesma tarefa de britar pedras. Indagado sobre o sentido de seu mister, um dos trabalhadores respondeu mal-humorado que nada mais fazia do que quebrar aquelas mal-ditas pedras. $O$ outro, ao revés, imbuído de motivação muito mais elevada, retrucou entusiasmado que estava ajudando a construir um templo ... assim, "romantismos" à parte, é razoável imaginar-se que um trabalha-dor que consegue vislumbrar, em sua atividade, um dever moral que por ele está sendo cumprido, realize suas tarefas de maneira bem diversa da que faz aquele que apenas considera estar labutando para prover os meios necessários à própria subsistência e à da sua família? A resposta só poderá ser afirmativa ou, pelo menos, deve ser tida por irrenunciável a ideia de que ela possa ser afirmativa. (LUCCA, 2009. PG. 339)

Do mesmo modo, ao interpretar-se a atividade empresarial ética e responsável como ativos intangíveis da empresa, vejamos, que dessa consequência e em virtude de elementos de confiança e segurança comercial que estas revelam no trato mercantil com seus clientes e investidores, a dimensão mercantil alarga-se, revelando benefícios de ordem econômica: 
Personalidade Acadêmica Homenageada:

Florisbal de Souza Del'Olmo (Professor Convidado - UNICURITIBA)

Uma empresa hígida merece confiança no trato financeiro, e estando esta empresa hígida financeiramente, o "mercado" à olha como sendo um bom parceiro comercial. Isto resulta em credibilidade no mercado e "ratings" cada vez maiores gerando uma elíptica positiva e dinâmica no crescimento da empresa.

Essa preocupação e essa política de credibilidade somente demonstram a estabilidade da empresa e sua confiabilidade, o que resulta inexoravelmente, para ela e seus parceiros econômicos novos negócios e lucros. Esses resultados são reflexos do amadurecimento e da vivência dos processos empresariais que conduzem a empresa a ser esse novo elemento catalisador da sociedade.

No aspecto do âmbito de trabalho interno, estas empresas que conformaram uma ética empresarial mais profunda em seu ambiente de trabalho, verificaram que este aspecto se tornou um objeto de desejo para pessoas que queiram trabalhar e necessitam de trabalhar comungando deste mesmo parâmetro de respeito e admiração.

Contextualmente, as empresas então começam a ser buscadas pelas melhores cabeças do mercado, e então revela-se que aquele ambiente eticamente saudável, não se torna mais um elemento empresarial, mas um objeto de desejo do trabalhador, que busca cada vez mais respeito, ambientes de trabalho mais equilibrados e remuneração condizentes.

Vejamos então que elementos como o RH das empresas, bem como produtividade, e ou mesmo fiscalização, começam a verificar que esse "ativo empresarial chamado ética" começa a ser uma mola propulsora de atitudes positivamente "corretas".

\section{O COMPLIANCE CONSUMERISTA: A EXPERIÊNCIA WALLMART}

Quando falamos em compliance consumerista, sempre nos vem à mente a imagem da lesão ao consumidor, ou problemas enfrentados na relação de consumo. Muito se estuda e muito se investe na proteção ao consumidor, desde as esferas 
Personalidade Acadêmica Homenageada:

Florisbal de Souza Del'Olmo (Professor Convidado - UNICURITIBA)

administrativas públicas, como pelos entes privados, em especial as empresas que tem como seu público alvo o consumidor final.

Nesse espectro de atuação, a relação de consumo caracterizada, portanto pelo consumo final, desdobra-se através do consumo eletrônico, modernamente utilizado, como aquele consumo de prateleira tradicional, perfazendo um universo imenso e dinâmico a que o consumidor está inserido.

Desta feita, não há dúvidas, que a exposição do consumidor à problemas referentes aos produtos, ou à prestação do serviço, são em sua origem um risco assumido pelo fabricante, ou pelo vendedor, mas que em sua dimensão meramente comercial, não reconhecem o alcance devido da relação consumerista, de responsabilidade sobre eventual fato ou vício do produto.

Diante dessa evidência, as empresas cada vez mais, vem criando instrumentos, para que essa responsabilidade seja minimizada, diminuída ou até mesmo extinta, buscando a otimização e diminuição de riscos, em prol da integridade da imagem da empresa.

Nesse contexto, é que surgem, portanto, os códigos de integridade, nome este dado pela lei anticorrupção, mas que cada vez mais, fazem parte do cotidiano empresarial, como forma de instituição de valores, na forma de códigos de condutas e códigos de ética.

Nesse momento é que escolhemos uma grande fornecedora de bens ao consumo em geral, para analisar seu código de ética bem como sua política em relação ao consumidor, visto ter em sua estrutura tanto a plataforma eletrônica como as lojas físicas.

Esse conjunto de plataformas de compras, a chamaremos conforme a política interna da empresa escolhida de MARKETPLACE. Sendo que esse marketplace eletrônico, possui regras específicas para seu ambiente:

Termos e Condições de Uso do Marketplace. Olá, Para que você possa utilizar o Marketplace do Walmart.com destacamos algumas informações da contratação do serviço e outros temas relevantes para facilitar a sua experiência no nosso Site: A - O que é o Marketplace do Walmart.com? Marketplace nada mais é do que um grande local de compras e vendas de produtos. No ambiente online isso se traduz em um espaço virtual no qual a 
Personalidade Acadêmica Homenageada:

Florisbal de Souza Del'Olmo (Professor Convidado - UNICURITIBA)

\begin{abstract}
empresa permite que outros lojistas anunciem seus produtos e serviços através do endereço eletrônico www.walmart.com.br. Assim, o Walmart.com é como se fosse um shopping center virtual, onde vários lojistas vendem seus produtos e serviços diretamente aos consumidores. Podemos dizer então que o Walmart.com é uma plataforma online, integrada ao portal www.walmart.com.br, onde um usuário Vendedor pode oferecer seus próprios produtos e/ou serviços diretamente a usuários Compradores. O serviço prestado pelo Walmart.com é o oferecimento desta plataforma aos usuários, com inúmeras funcionalidades, permitindo que usuários Vendedores e Compradores se aproximem e realizem transações diretamente entre si. $^{2}$
\end{abstract}

Traduzido, portanto esse ambiente digital, vemos com muita clareza que as dimensões consumeristas, já transbordaram o comércio tido de "prateleira", criando uma ciber-fronteira, onde há uma necessidade de fiscalização e proteção integral ao direito do consumidor.

Vê-se, portanto, que a figura virtual da loja e do consumidor, assumem novo papel comercial e social, transformando a relação de consumo, em uma troca digital de informações, pela aquisição do produto a ser entregue ao consumo.

Esse ambiente digital, embora distante da realidade física do consumidor, transformou a proteção do consumidor, realocando a proteção integral dessa relação, não só ficado na qualidade do produto, mas também nessa espécie de prestação de serviço "digital", que é a compra no ambiente "de marketplace".

Esse olhar, sobre o maketplace, traduz a amplitude e o alcance da esfera consumerista, pois atinge a compra como processo de troca de valores, entre fornecedor e consumidor, afeta diretamente a troca de informações entre consumidor e fornecedor, afeta a correta manutenção da plataforma de "marketplace", bem como proteção às informações prestadas, para que ao final, seja corretamente enviado o produto, de acordo com as especificações de compra, e este produto seja entregue com sua integridade que se espera ao consumidor final.

Essa complexa ramificações de atribuições, só é possível através da implantação de valores éticos da empresa. Nesse contexto vemos com certa clareza que o pano de fundo de caráter meramente valorativo, se expande aos colaboradores e partem de forma axiológica dentro da empresa, como forma de

\footnotetext{
${ }^{2}$ https://www.walmart.com.br/institucional/termos-uso-marketplace
} 
Personalidade Acadêmica Homenageada:

Florisbal de Souza Del'Olmo (Professor Convidado - UNICURITIBA)

verticalização de valores a serem impressos em todos os processos internos da empresa.

Dentro do código de ética da empresa WALLMART, podemos encontrar:

\begin{abstract}
Respeito pelo indivíduo - Valorizamos todos os associados, nos responsabilizamos pelo trabalho que fazemos e nos comunicamos ouvindo e compartilhando ideias. Busca pela excelência - Trabalhamos em equipe e damos exemplos positivos ao mesmo tempo em que inovamos e melhoramos todos os dias. Agir com integridade - Agimos com o mais elevado padrão de integridade, sendo objetivos, justos e honestos, e operamos em conformidade com todas as leis e nossas políticas. Superar as expectativas de nossos clientes. Estamos aqui para servir nossos clientes, apoiarmos uns aos outros e nos dedicarmos às comunidades locais. Visão do Departamento de Ética Promover o comprometimento com a cultura ética do Walmart para todos os públicos envolvidos em nosso negócio de maneira global.(retirado do código de ética wallmart - disponível em www.wallmart.com.br)
\end{abstract}

Vejamos, portanto, que a valorização de todos os envolvidos no processo se dá através pelo compartilhamento de ideias e condutas, o que traduz verdadeiro respeito ao consumidor.

Nesse espectro, portanto, servir ao consumidor, e a todos os clientes é de certa forma apoias a comunidade local, pelo pacto de não-lesão, fazendo com que as experiências e expectativas dos clientes sejam superadas.

Nessa busca pela Excelência de atendimento, a busca incessante pela demonstração de bons exemplos, criam a força centrifuga administrativa, para superação e melhoramento dos processos administrativos os quais ultrapassam as barreiras da empresa e mudam o modo de pensar de todos os envolvidos.

Essa integridade no agir constrói, portanto, um novo padrão de comportamento, o qual vai se enraizando na cultura da empresa, se alastrando pela sociedade, como forma objetiva, clara e justa, de se conformar com as leis consumeristas e as políticas de integridade da própria empresa. 
Personalidade Acadêmica Homenageada:

Florisbal de Souza Del'Olmo (Professor Convidado - UNICURITIBA)

\title{
4 DAS POLÍTICAS DE PRIVACIDADE
}

Uma das questões atinentes à ética empresarial, e ao market place cinge-se acerca das políticas de privacidade e de proteção às informações dos consumidores. Da mesma forma, os termos de uso e condições, bem como políticas da empresa precisam estar expressos como forma de respeito ao direito de informação do consumidor.

No que tange a política de privacidade, a experiência Wallmart, traduz numa séria e rigorosa, política que extensivamente coloca a própria empresa integralmente responsável pela guarda destas informações, o que novamente denota o respeito ao seu cliente final.

\begin{abstract}
A Política de Privacidade do Walmart.com foi elaborada para reafirmar o nosso compromisso com a privacidade e a segurança das informações que coletamos de nossos Usuários e Internautas. A presente política abrange o tratamento que o Walmart.com dá as informações capazes de identificar os Internautas, Usuários ou Clientes sejam as coletadas diretamente neste Portal, sejam as armazenadas em sua base de dados eletrônica por outros meios de coleta, tais como cadastros preenchidos em meio físico ou consultas à Central de atendimento Walmart.com.
\end{abstract}

Dentro dos objetivos cumpre enunciar, que a política de privacidade, estatui, não só a proteção do marketplace, bem como seu aprimoramento, e seu desenvolvimento:

2.1. Uma das principais diretrizes do Walmart.com é o respeito pelo indivíduo. Assim, temos o compromisso de manter suas informações pessoais e informações de acesso sob o mais completo sigilo, vinculandoas unicamente ao seu registro e utilizando-as unicamente para: Realizar a entrega e a cobrança dos produtos adquiridos e serviços prestados pelo Portal Walmart.com, incluindo os produtos e serviços ofertados aos Terceiros Anunciantes ou Usuários Vendedores, bem como a identificação do respectivo destinatário; Cumprir obrigações legais de qualquer natureza; Obter estatísticas genéricas para identificação do perfil dos nossos Internautas e desenvolvimento de nossas campanhas; Manutenção de dados e ações de relacionamento com o Usuário, bem como a melhoria contínua do serviço prestado pelo Portal Walmart.com; Resolução de eventuais questões legais relacionadas ao Portal Walmart.com; Melhoria da experiência do usuário no Portal Walmart.com, por meio de ofertas específicas e direcionadas, além da prática de marketing direcionado, de acordo com o seu perfil; 
Personalidade Acadêmica Homenageada:

Florisbal de Souza Del'Olmo (Professor Convidado - UNICURITIBA)

Vejamos que a obtenção dessas informações, capazes de gerar a responsabilidade da empresa são tratadas como sigilosas, e são incorporadas à base de dados da empresa, se tornando verdadeiros ativos.

Ou seja, uma empresa eticamente relevante, e com o compromisso de não lesão ao consumidor, transforma o ambiente digitalmente seguro, em verdadeiro ativo da empresa.

Vê-se, portanto, que ambiente digital seguro, e agregado com valores de respeito as relações de consumo, pautadas inclusive pela ética empresarial, se tornam ambientes virtuosos, capazes de gerar negócios, comercialmente interessantes, e lucrativos.

Veja que em nenhum momento, tentamos minimizar as responsabilidades empresarial, mas ao contrário, é de extrema facilidade demonstrar que o ambiente comercial pautado pelo respeito as regras consumeristas e apoiado por um vértice ético empresarial, criam um elo virtuoso de negócios, atrativos ao consumidor, que se apoia na segurança de sua compra, como fator elementar de escolha por aquela empresa.

O Walmart.com fará todo o possível para manter a privacidade das informações pessoais e informações de acesso armazenados em seus servidores, comprometendo-se a utilizar tecnologia que seja suficientemente adequada para a proteção de tais dados, procurando manter o ambiente seguro, com uso de ferramentas apropriadas e controles eficientes de segurança das informações coletadas, sempre observando o estado da técnica disponível. Contudo, considerando que nenhum sistema de segurança é absolutamente seguro, o Walmart.com se exime de quaisquer responsabilidades por eventuais danos e/ou prejuízos decorrentes de invasões no Portal Walmart.com, em seus servidores e demais falhas relacionadas, salvo se houver dolo ou culpa do Walmart.com.

Em recente pesquisa aos sistemas de proteção ao consumidor, fornecido pelo PROCON de São Paulo, encontramos um extensa lista ${ }^{3}$ de "sistemas"

${ }^{3}$ http://sistemas.procon.sp.gov.br/evitesite/list/evitesites.php - Fonte: Fundação Procon/SP Listagem atualizada em: 26/04/2018 A listagem está em ordem alfabética pelo endereço (URL) do site, caso prefira outra ordem clique no título da coluna *A situação do site se refere a data da inserção na lista 


\section{Personalidade Acadêmica Homenageada:}

\section{Florisbal de Souza Del'Olmo (Professor Convidado - UNICURITIBA)}

eletrônicos, ou endereços de compras eletrônicas que o consumidor deve evitar. Nessa lista não consta o site da www.wallmart.com.

Este exemplo é muito claro, pois o chamado marketplace, revela acima de tudo respeito à legislação, mas sobretudo demonstra uma pauta ético-empresarial em relação ao seu cliente, sendo este seu maior ativo, o respeito ao cliente.

\section{CONCLUSÃO}

Creio estarmos frente a um novo parâmetro empresarial na qual demonstra um caminho somente de mão única, fazendo com as empresas façam a adesão a esse novo pacto social. Tais elementos tomaram a consciência da atividade empresarial, e aqueles sentimentos éticos exercem uma considerada conformidade no espectro da atuação empresarial e comercial.

Conceitos éticos nas relações consumeristas cada vez mais se mostram como verdadeiras realidades postas. O desenvolvimento de governança corporativa, e ao final o que chamamos de accountability, são elementos do novo tripé empresarial com vistas à atuação ética e responsável.

Os benefícios da implantação dos códigos de compliance, ou códigos de integridade, reforçam o valor deste instrumento, não só ético, mas trazem consigo, possibilidades empresariais intrínsecas, como o aumento de credibilidade de mercado.

Assim ao criar um ambiente favorável à atividade laborativa, mais uma vez a empresa torna-se cobiçada pelo ambiente de trabalho, atraindo para os seus corpos internos, pessoas engajadas, motivadas, e pautadas por esse novo cenário ético estrutural da empresa.

No que tange à modificação social que essas empresas possuem, basta mencionar, que aquele colaborador, que aderiu às novas regras de conduta, começa a se pautar por aquele novo patamar ético-cultural. Dessa forma, cria-se um elemento modificador da sociedade, onde aquela pessoa inserida torna-se um 


\section{Personalidade Acadêmica Homenageada:}

\section{Florisbal de Souza Del'Olmo (Professor Convidado - UNICURITIBA)}

disseminador dessas ideias e condutas, demonstrando, portanto, um caminho viável ao sucesso, e ao progresso social e econômico.

Dessa representatividade, extraímos que a atividade empresarial conformada através de um código de integridade, ou um código de conduta éticomoral, é, portanto, fator catalisador de modificação do pensamento social, e do ser humano.

Essa contribuição dada pela atividade empresarial, deve ser encarada como a verdadeira função social da empresa, a qual tem como escopo a modificação da sociedade através do exemplo que esta deve dar através de sua atividade fim.

Assim, diante da nova configuração do direito empresarial, e do novo cenário empresarial, onde se busca cada vez mais a conformidade de comportamento afim de minimizar os riscos à integridade da empresa, percebe-se que a possibilidade de uma ética empresarial é urgente e necessária.

O direito empresarial, e a empresa não podem mais serem passivos observadores e receptores dos dados da vida empresarial. $\mathrm{O}$ ambiente empresarial começa a atuar mais do que tudo: prevenindo, detectando e reagindo atitudes ou condutas que possam gerar riscos empresariais.

No âmbito do compliance, a construção de valores, a defesa de padrões éticos da atividade empresarial faz a promoção e a preservação da atividade fim mercantil, pensando sempre na redução de custos para este controle, como caminho para promoção da vida sócio-empresarial.

Esse reflexo do conjunto de medidas e valores centrais orienta, organiza e vincula todos os envolvidos na realização de um bem maior seja este a modificação da cultura, através de um compromisso empresarial. E existência destes códigos de conduta, transcendem a ética social e empresarial, alcançando pela promoção de valores das pessoas que nela trabalham e da comunidade na qual deve integrar-se. Nesse desempenho dessa função encontramos o mais nobre estímulo à auto realização social. 
Personalidade Acadêmica Homenageada:

Florisbal de Souza Del'Olmo (Professor Convidado - UNICURITIBA)

\section{REFERÊNCIAS}

BOLTANSKI, Luc e CHIAPELLO, Eve. O NOVO ESPÍRITO DO CAPITALISMO. LuC Boltanski e Luc Chiapello, São Paulo, Editora Martins Fontes, 2009.

GRAU, Eros Roberto. A Ordem Econômica na Constituição de 1988 (interpretação e crítica), 12 edições. São Paulo. Ed. Malheiros, 2012.

LUCCA, Newton De. Da ética Geral à ética empresarial - São Paulo, Quartier Latin, 2009.

SANTOS, Boaventura de Souza. A Globalização e as ciências sociais/ Boaventura de Souza Santos (org.) - 2 ed. São Paulo Cortez, 2002.

WALLMART. Disponível em: www.wallmart.com.br

CÓDIGO DE ÉTICA - WALLMART - podendo ser encontrado em www.wallmart.com.br 